\title{
Prevalence and Characteristics of Neuropathic Pain in Patients With Spinal Cord Injury Referred to a Rehabilitation Center
}

\author{
Hae Young Kim, MD, Hye Jin Lee, MD, Tae-lim Kim, MD, Eun Young Kim, MD, \\ Daehoon Ham, MD, Jaejoon Lee, MD, Tayeun Kim, MD, Ji Won Shin, MD, \\ Minkyoung Son, MD, Jun Hun Sung, MD, Zee-A Han, MD
}

Department of Rehabilitation Medicine, National Rehabilitation Center, Seoul, Korea

Objective To identify the prevalence and characteristics of neuropathic pain (NP) in patients with spinal cord injury (SCI) and to investigate associations between NP and demographic or disease-related variables.

Methods We retrospectively reviewed medical records of patients with SCI whose pain was classified according to the International Spinal Cord Injury Pain classifications at a single hospital. Multiple statistical analyses were employed. Patients aged $<19$ years, and patients with other neurological disorders and congenital conditions were excluded.

Results Of 366 patients, 253 patients (69.1\%) with SCI had NP. Patients who were married or had traumatic injury or depressive mood had a higher prevalence rate. When other variables were controlled, marital status and depressive mood were found to be predictors of NP. There was no association between the prevalence of NP and other demographic or clinical variables. The mean Numeric Rating Scale (NRS) of NP was 4.52, and patients mainly described pain as tingling, squeezing, and painful cold. Females and those with below-level NP reported more intense pain. An NRS cut-off value of 4.5 was determined as the most appropriate value to discriminate between patients taking pain medication and those who did not.

Conclusion In total, $69.1 \%$ of patients with SCI complained of NP, indicating that NP was a major complication. Treatment planning for patients with SCI and NP should consider that marital status, mood, sex, and pain subtype may affect NP, which should be actively managed in patients with an NRS $\geq 4.5$.

Keywords Spinal cord injuries, Neuralgia, Pain

Received April 23, 2020; Revised May 22, 2020; Accepted June 3, 2020; Published online December 31, 2020

Corresponding author: Hye Jin Lee

Department of Rehabilitation Medicine, National Rehabilitation Center, 58 Samgaksan-ro, Gangbuk-gu, Seoul 01022, Korea. Tel: +82-2-901-1886, Fax: +82-2-902-3835, E-mail: ludin80@gmail.com

ORCID: Hae Young Kim (http://orcid.org/0000-0001-5635-7349); Hye Jin Lee (http://orcid.org/0000-0001-9400-6283); Tae-lim Kim (http://orcid. org/0000-0001-6671-977X); EunYoung Kim (http://orcid.org/0000-0002-3122-7596); Daehoon Ham (http://orcid.org/0000-0002-3444-5951); Jaejoon Lee (http://orcid.org/0000-0002-7324-8424); Tayeun Kim (http://orcid.org/0000-0002-8826-825X); Ji Won Shin (http://orcid.org/0000-0002-62273413); Minkyoung Son (http://orcid.org/0000-0001-7218-2577); Jun Hun Sung (http://orcid.org/0000-0002-3217-5484); Zee-A Han (http://orcid. org/0000-0002-8070-2218).

(c) This is an open-access article distributed under the terms of the Creative Commons Attribution Non-Commercial License (http://creativecommons.org/ licenses/by-nc/4.0) which permits unrestricted noncommercial use, distribution, and reproduction in any medium, provided the original work is properly cited. Copyright () 2020 by Korean Academy of Rehabilitation Medicine 


\section{INTRODUCTION}

Chronic pain is a common secondary complication in patients with spinal cord injury (SCI), and between $65 \%$ and $85 \%$ of patients with SCI have reported pain symptoms [1,2]. Moreover, one-third of these patients have characterized their pain as severe [3]. Patients with SCI have reported many pain types, the most prevalent of which is musculoskeletal pain frequently localized in the shoulder, wrist, and back, which is reported to be common in both acute and chronic phases due to overuse or muscle weakness [3]. In recent studies, neuropathic pain (NP) has been found to be as common as musculoskeletal pain [4], and is often considered to involve the most severe pain, presenting at and/or below the neurological injury level $[3,5]$. Of patients with SCI, $>50 \%$ have reported more than one pain type [6]. In addition, pain has been reported to persist and worsen with time [3], and to have a negative effect on a person's physical, psychological, and social functioning [7].

After an SCI, patients often report the onset of NP caudal to the level of the lesion or at the same level within the associated spinal cord segment. Between $10 \%$ and $30 \%$ of patients with SCI have been reported to experience severe NP sufficient to interfere with their activities of daily living [8]. Patients with SCI and NP have been reported to require more healthcare resources, such as inpatient admissions, emergency department visits, consultations with physicians, SCI- and pain-related procedures, physical therapy, and outpatient prescriptions than those without NP, resulting in an additional cost of $\$ 22,545$ per patient per annum for total healthcare expenditure after NP onset in a commercially insured population in the United States [9]. NP has been shown to be a major cause of distress in patients with SCI, and both pain and pain-related psychological distress interfere with patient participation in SCI-related rehabilitation and quality of daily life $[10,11]$.

Therefore, it is important to diagnose and manage NP in SCI patients early and, to this end, there are a variety of SCI NP diagnostic tools available. Specific tools used to evaluate NP in patients with SCI include the McGill Pain Questionnaire, the Leeds Assessment of Neuropathic Symptoms and Signs, and the International Association for the Study of Pain (IASP) guidelines, which are limited in terms of distinguishing all types of pain associated with or without SCI. Moreover, many previous studies have used different classification methods; therefore, there has been wide variation in the reported dynamics of NP.

The International Spinal Cord Injury Pain (ISCIP) classification, a mechanism-based classification that distinguishes between nociceptive pain, NP, other pain, and unknown pain in patients with SCI, has been validated by the American Spinal Injury Association (ASIA) and the International Spinal Cord Society (ISCoS) [5]. It sets a standard of pain classification for patients with SCI, in an attempt to replace previous classifications that have led to widespread confusion in previous studies.

In South Korea, there has been variation in SCI-related pain study results due to a lack of a unified classification, and few epidemiological investigations regarding the prevalence and characteristics of NP in patients with SCI have been undertaken, despite the availability of many evaluation methods.

Therefore, we aimed to identify the prevalence and characteristics of NP in patients with SCI using the ISCIP classification, which has greater reliability, and to investigate associations between NP and demographic or disease-related variables.

\section{MATERIALS AND METHODS}

\section{Study patients}

In this descriptive cross-sectional study, the medical records of patients with SCI admitted to the National Rehabilitation Center, Seoul, Republic of Korea between January 1, 2016 and December 31, 2017 were collected using a standardized form. Inclusion criteria comprised patients with an SCI whose pain records had been classified according to the ISCIP classification. Patients aged $<19$ years and patients diagnosed with other neurological disorders (for example, Parkinson disease, multiple sclerosis, traumatic brain injury, and Guillain-Barré syndrome) and congenital conditions (spina bifida, cerebral palsy) were excluded.

\section{Clinical data collection}

We recorded the demographic data (age, sex, marital status, occupational data, and educational status) and medical conditions (onset of injury, cause of injury, operation status, complications, and medication on admis- 
sion) of each patient.

We evaluated the neurological function of patients with SCI using the ASIA impairment scale, which determines the neurological level of injury (NLI) and the extent of injury, according to the International Standards for Neurological Classification of Spinal Cord Injury (ISNCSCI) [12].

Concerning patients with pain, pain intensity was defined on a $0-10$ Numerical Rating Scale (NRS) ( $0=$ no pain and $10=$ worst possible pain), and pain characteristics were assessed according to the three tiers of the ISCIP classification, as follows [5]:

Tier 1: Pain type (nociceptive pain, NP, other pain, or unknown pain).

Tier 2: Pain subtype (musculoskeletal pain, visceral pain, other nociceptive pain, at-level SCI pain, below-level SCI pain, or other NP).

Tier 3: Primary pain source and/or pathology.

Nociceptive pain was defined as "pain arising from activation of nociceptors", where a nociceptor is defined as "a sensory receptor that is capable of transducing and encoding noxious stimuli". Subtypes of nociceptive pain include musculoskeletal pain, visceral pain, and other nociceptive pain. NP was defined as "pain caused by a lesion or disease of the somatosensory nervous system". In SCI, NP is subdivided into at-level SCI (neuropathic) pain, below-level SCI (neuropathic) pain, and other (neuropathic) pain, whereas the latter is unrelated to SCI. At-level SCI pain refers to NP due to spinal cord or nerve root damage that occurs at the NLI and/or within three dermatomes below the NLI, but not in any lower dermatomes. Pain that was considered due to cauda equina damage was also classified as at-level SCI pain. Belowlevel SCI pain involved pain perceived more than three levels below the NLI, and was considered to be due to a lesion or disease affecting the spinal cord. Pain was classified as "other pain" if there was no detectable noxious stimulus, inflammation, or damage to the nervous system responsible for the pain. If a pain type could not be clearly assigned to any of the aforementioned categories, it was classified as "unknown pain".

Assessment of depressive severity was determined using self-rating screening tools, namely, the Beck Depression Inventory 2nd edition (BDI-II) or the Geriatric Depression Scale (GDS). The BDI-II consists of 21 items, with possible scores ranging from 0 to 3 , and is used to assess levels of depression (cognitive, affective, somatic, and vegetative symptoms of depression). The cut-off scores are as follows: 0-13, minimal; 14-19, mild; 20-28, moderate, and 29-63, severe depression [13]. The GDS is a 30-item questionnaire in which patients are requested to respond "yes" or "no" in reference to how they have been feeling over the past week. Scores of 0-13 are considered normal; 14-18 indicate mild depression; 19-21 indicate moderate depression, and 22-30 indicate severe depression [14]. Patients aged $\geq 65$ years undertook a GDS, whereas other patients undertook a BDI-II.

Spasticity was estimated using the Modified Ashworth Scale (MAS), a reliable clinical scale used to measure muscle spasticity in spinal cord injuries-ranging from 0 (no spasticity) to 4 (rigid in flexion or extension) [15]. We classified those with an MAS score of zero as a group with no spasticity and those with an MAS score of $>1$ as a group with spasticity. Functional status was evaluated using the Korean version of the Spinal Cord Independence Measure 3rd edition (KSCIM-III) and the mode of locomotion (ambulation vs. wheelchair use). The KSCIM-III tool is used to evaluate the daily independent living index for patients with SCI, with a high degree of confidence in terms of its reliability and validity. The KSCIM-III comprises 19 items with 3 subscales: self-care (6 items, 0-20 points), respiration and sphincter management (4 items, $0-40$ points), and mobility (9 items, $0-40$ points). Mobility is further categorized into room and toilet mobility (3 items, $0-10$ points) and indoor and outdoor mobility (6 items, $0-30$ points) [16].

\section{Institutional Review Board approval}

In October 2018, we obtained approval from the Institutional Review Board of the National Rehabilitation Center to undertake this study (No. NRC-2018-06-039). The study duration was 12 months, from February 20, 2019 to February 19, 2020. As this study involved a retrospective design with anonymized data, a requirement for informed patient consent was waived. The Declaration of Helsinki was upheld.

\section{Statistical analysis}

Statistical analyses were performed using the Statistical Package for Social Sciences (SPSS) version 20 software (IBM, Armonk, NY, USA). A descriptive analysis was performed on the demographic, clinical, and pain-related characteristics. Data are presented as mean \pm standard 
deviations and percentages. To evaluate correlations between the prevalence of NP and other variables, a $\chi^{2}$ test and linear-by-linear associations were used. Logistic regression analysis was used to analyze the contribution of single variables after adjusting for other variables. An independent t-test and a one-way ANOVA and Pearson correlation coefficient (r) were used for the calculation of correlations between pain intensity and other variables. A receiver operating characteristic (ROC) curve analysis was performed to determine the cut-off value of the NRS, to provide the best values concerning sensitivity and specificity for estimating pain severity clinically, in terms of a therapeutic threshold for medication. The p-values $<0.05$ were considered to be statistically significant.

\section{RESULTS}

During the period from January 1, 2016 to December $31,2017,439$ patients with SCI were admitted to the Na-

Table 1. Demographic characteristics of the study participants

\begin{tabular}{|cc|}
\hline \multicolumn{1}{c}{ Characteristic } & Value \\
\hline Sex & $270(73.8)$ \\
\hline Male & $96(26.2)$ \\
\hline Female & $53.87 \pm 15.94$ \\
\hline Age $(\mathrm{yr})$ & $31(8.5)$ \\
\hline $20-29$ & $45(12.3)$ \\
\hline $30-39$ & $61(16.7)$ \\
\hline $40-49$ & $87(23.8)$ \\
\hline $50-59$ & $78(21.3)$ \\
\hline $60-69$ & $64(17.5)$ \\
\hline$\geq 70$ & \\
\hline Marital status & $255(69.7)$ \\
\hline Married & $111(30.3)$ \\
\hline Single & \\
\hline Occupation & $264(72.1)$ \\
\hline Employed & $102(27.9)$ \\
\hline Unemployed & \\
\hline Educational status & $38(10.4)$ \\
\hline Primary school graduate or lower & $46(12.6)$ \\
\hline Middle school graduate & $151(41.3)$ \\
\hline High school graduate & $131(35.8)$ \\
\hline College graduate or higher & \\
\hline
\end{tabular}

Values are presented as number (\%) or mean \pm standard deviation. tional Rehabilitation Center. We excluded 73 patients from the analysis due to a diagnosis of other neurological disorders or congenital conditions, and patients aged $<19$ years old. Finally, we analyzed data concerning 366 patients, of whom $253(69.1 \%)$ patients had NP and 113 had no NP, according to the ISCIP classification.

\section{Prevalence of NP}

The demographic characteristics of the included patients are summarized in Table 1. The prevalence of NP according to each group is shown in Table 2 . The pain prevalence among females $(72 / 96,75.0 \%)$ was slightly

Table 2. Prevalence of neuropathic pain according to each demographic variable

\begin{tabular}{|c|c|c|c|}
\hline Demographic variable & $\mathbf{n}$ & Prevalence & p-value \\
\hline Sex & & & 0.14 \\
\hline Male & 270 & $181(67.0)$ & \\
\hline Female & 96 & $72(75.0)$ & \\
\hline Age (yr) & & & 0.94 \\
\hline$<50$ & 137 & $95(69.3)$ & \\
\hline$\geq 50$ & 229 & $158(69.0)$ & \\
\hline Marital status & & & $0.008^{*}$ \\
\hline Married & 255 & $187(73.3)$ & \\
\hline Single & 111 & $66(59.5)$ & \\
\hline Occupation & & & 0.52 \\
\hline Employed & 264 & $185(70.1)$ & \\
\hline Unemployed & 102 & $68(66.7)$ & \\
\hline Educational status & & & 0.87 \\
\hline $\begin{array}{l}\text { Primary school graduate or } \\
\text { lower }\end{array}$ & 38 & $25(65.8)$ & \\
\hline Middle school graduate & 46 & $34(73.9)$ & \\
\hline High school graduate & 151 & $104(68.9)$ & \\
\hline College graduate or higher & 131 & $90(68.7)$ & \\
\hline Depression severity & & & $0.001^{* *}$ \\
\hline $\begin{array}{l}\text { None } \\
\text { (BDI-II 0-13, GDS 0-13) }\end{array}$ & 168 & $108(64.3)$ & \\
\hline $\begin{array}{l}\text { Mild } \\
\text { (BDI-II 14-19, GDS 14-18) }\end{array}$ & 50 & $32(64.0)$ & \\
\hline $\begin{array}{l}\text { Moderate } \\
\text { (BDI-II 20-28, GDS 19-21) }\end{array}$ & 30 & $25(83.3)$ & \\
\hline Severe (BDI-II 29-, GDS 22-) & 31 & $28(90.3)$ & \\
\hline
\end{tabular}

Values are presented as number (\%).

BDI-II, Beck Depression Inventory 2nd edition; GDS, Geriatric Depression Scale.

${ }^{*} \mathrm{p}<0.05$ according to Pearson chi-square test, ${ }^{* *} \mathrm{p}<0.05$ according to the linear-by-linear association test. 
higher than that among males (181/270, 67.0\%), but this difference was not statistically significant $(\mathrm{p}=0.14)$. In married patients with SCI, the prevalence of NP (187/255, $73.3 \%$ ) was significantly higher than that in single pa-

Table 3. Prevalence of neuropathic pain according to each clinical variable

\begin{tabular}{|c|c|c|c|}
\hline Clinical variable & $\mathbf{n}$ & Prevalence & p-value \\
\hline Onset & & & 0.57 \\
\hline Acute ( $<6$ months $)$ & 196 & $133(67.9)$ & \\
\hline Chronic ( $\geq 6$ months) & 170 & $120(70.6)$ & \\
\hline Type of injury & & & 0.19 \\
\hline Complete & 111 & $82(73.9)$ & \\
\hline Incomplete & 255 & $171(67.1)$ & \\
\hline ASIA impairment scale & & & 0.16 \\
\hline A & 111 & $82(73.9)$ & \\
\hline B & 41 & $23(56.1)$ & \\
\hline $\mathrm{C}$ & 60 & $44(73.3)$ & \\
\hline $\mathrm{D}$ & 154 & $104(67.5)$ & \\
\hline NLI & & & 0.80 \\
\hline Cervical & 190 & $131(68.9)$ & \\
\hline Thoracic & 121 & $82(67.8)$ & \\
\hline Lumbar & 55 & $40(72.7)$ & \\
\hline Type of injury \& NLI & & & 0.53 \\
\hline Complete, paraplegia & 55 & $42(76.4)$ & \\
\hline Incomplete, paraplegia & 123 & $84(68.3)$ & \\
\hline Complete, tetraplegia & 56 & $40(71.4)$ & \\
\hline Incomplete, tetraplegia & 132 & $87(65.9)$ & \\
\hline Etiology of injury & & & $0.02^{*}$ \\
\hline Traumatic & 242 & $177(73.1)$ & \\
\hline Non-traumatic & 124 & $76(61.3)$ & \\
\hline Locomotion & & & 0.31 \\
\hline Wheelchair dependent & 293 & $199(67.9)$ & \\
\hline Gait & 73 & $54(74.0)$ & \\
\hline Operation & & & 0.06 \\
\hline Performed & 319 & $226(70.8)$ & \\
\hline Not performed & 47 & $27(57.4)$ & \\
\hline Spasticity & & & 0.79 \\
\hline Spastic & 156 & $109(69.9)$ & \\
\hline None & 210 & $144(68.6)$ & \\
\hline
\end{tabular}

Values are presented as number (\%).

ASIA, American Spinal Injury Association; NLI, neurological level of injury.

${ }^{*} \mathrm{p}<0.05$ according to Pearson chi-square test. tients $(66 / 111,59.5 \%)(\mathrm{p}=0.008)$. Outcomes concerning 279 patients who completed the BDI-II or the GDS are reported in Table 2. Our findings showed that, when patients with NP were classified into groups in terms of no depression or mild, moderate, and severe depression, according to the criteria of each assessment tool and then combined, the more depressed a group was, the higher the prevalence of NP $(p=0.001)$. There was no association between the prevalence of NP and other demographic variables.

The prevalence of NP among the groups classified according to each clinical variable is shown in Table 3 . The prevalence of NP was $67.9 \%$ in patients with acute SCI and $70.6 \%$ in patients with chronic SCI. The prevalence of NP was $73.9 \%$ in patients with complete SCI, which was higher than for patients with incomplete SCI (67.1\%) $(\mathrm{p}=0.19)$. In terms of the NLI, or in the combined type and NLI, there was no significant difference between each group. The prevalence of NP was $73.1 \%$ in patients with traumatic SCI, which was significantly higher than that in patients with non-traumatic SCI $(61.3 \%)(\mathrm{p}=0.02)$. No statistically significant contribution to the prevalence of NP was found in the groups classified according to patient functional status, operation status, and spasticity.

We performed logistic regression analysis to analyze the contribution of single variables after adjusting for other variables. In the logistic regression analysis, only marital status and depressive mood were predictors of NP $(\mathrm{p}=0.04$ and $p=0.01$, respectively). No statistically significant contribution to the prevalence was found according to the etiology of injury groups $(\mathrm{p}=0.09)$.

\section{Characteristics of NP}

NP-related characteristics are reported in Table 4. In total, of 253 patients who had NP, 232 patients (91.7\%) had below-level SCI pain, 32 patients (12.6\%) had at-level SCI pain, and 15 patients $(5.9 \%)$ had both at-level and belowlevel SCI pain. The mean NRS score was $4.52 \pm 1.80$ and tingling (50.6\%) was the most common pain description for patients with SCI, followed by squeezing (6.3\%), painful cold (6.3\%), and hot burning pain (5.5\%). Regarding pain medication, we included all pain-related drugs that had been prescribed for each patient. Of patients with NP, $73.1 \%$ had been prescribed anti-epileptic medication (gabapentin, 37.5\%; pregabalin, 35.6\%); opioids, $44.7 \%$ (tramadol, $33.2 \%$; other opioids, $11.5 \%$ ); analge- 
Table 4. Pain-related characteristics of neuropathic pain

\begin{tabular}{|cc}
\hline \multicolumn{1}{|c}{ Characteristic } & Value \\
\hline Pain subtype & $32(12.6)$ \\
\hline At-level & $232(91.7)$ \\
\hline Below-level & $7(2.8)$ \\
\hline Other & $4.52 \pm 1.80$ \\
\hline Pain intensity (NRS) & \\
\hline Pain description & $128(50.6)$ \\
\hline Tingling & $16(6.3)$ \\
\hline Squeezing & $16(6.3)$ \\
\hline Painful cold & $14(5.5)$ \\
\hline Hot-burning & $8(3.2)$ \\
\hline Electric shock-like & $6(2.4)$ \\
\hline Shooting & $4(1.6)$ \\
\hline Pricking & $3(1.2)$ \\
\hline Sharp & $91(36.0)$ \\
\hline No response & \\
\hline Pain medication & $95(37.5)$ \\
\hline Gabapentin & $90(35.6)$ \\
\hline Pregabalin & $84(33.2)$ \\
\hline Tramadol & $75(29.6)$ \\
\hline Acetaminophen & $44(17.4)$ \\
\hline NSAID & $37(14.6)$ \\
\hline TCA & $29(11.5)$ \\
\hline Other opioids & $10(4.0)$ \\
\hline SSRI/SNRI/SARI & $3(1.2)$ \\
\hline Benzodiazepines & $49(19.4)$ \\
\hline None & \\
\hline
\end{tabular}

Values are presented as number (\%) or mean \pm standard deviation.

NRS, Numerical Rating Scale; NSAID, non-steroidal anti-inflammatory drug; TCA, tricarboxylic acid; SSRI, selective serotonin reuptake inhibitor; SNRI, serotoninnorepinephrine reuptake inhibitor; SARI, serotonin antagonist reuptake inhibitor.

sics, $47.0 \%$ (acetaminophen, 29.6\%; non-steroidal antiinflammatory drugs [NSAIDs], $17.4 \%$ ); tricyclic antidepressants (TCAs), $14.6 \%$; selective serotonin reuptake inhibitors (SSRIs)/serotonin and norepinephrine reuptake inhibitors (SNRIs)/serotonin antagonist and reuptake inhibitors (SARIs), 4.0\%; and benzodiazepines, $1.2 \%$.

The correlation between NP intensity and medical factors

The mean pain intensity according to demographic or
Table 5. Intensity of neuropathic pain according to each demographic or clinical variable

\begin{tabular}{lcc}
\hline \multicolumn{1}{|c}{ Variable } & $\begin{array}{c}\text { Pain intensity } \\
\text { (NRS) }\end{array}$ & p-value \\
\hline Sex & & $0.03^{*}$ \\
\hline Male & $4.37 \pm 1.79$ & \\
\hline Female & $4.90 \pm 1.79$ & \\
\hline Age (yr) & & 0.59 \\
\hline$<50$ & $4.60 \pm 1.67$ & \\
\hline$\geq 50$ & $4.47 \pm 1.88$ & \\
\hline Marital status & & 0.90 \\
\hline Married & $4.53 \pm 1.89$ & \\
\hline Single & $4.50 \pm 1.53$ & \\
\hline Occupation & & 0.45 \\
\hline Employed & $4.47 \pm 1.77$ & \\
\hline Unemployed & $4.66 \pm 1.88$ & \\
\hline Educational status & & 0.32 \\
\hline Primary school graduate or & $4.64 \pm 1.96$ & \\
\hline lower & & \\
\hline Middle school graduate & $4.97 \pm 1.75$ & \\
\hline High school graduate & $4.53 \pm 1.88$ & \\
\hline College graduate or higher & $4.31 \pm 1.67$ & \\
\hline Depression severity & & 0.82 \\
\hline None (BDI-II 0-13, GDS 0-13) & $4.40 \pm 1.76$ & \\
\hline Mild (BDI-II 14-19, GDS & $4.59 \pm 1.93$ & \\
\hline 14-18) & & \\
\hline Moderate (BDI-II 20-28, GDS & $4.44 \pm 1.26$ & \\
\hline 19-21) & & \\
\hline Severe (BDI-II 29-, GDS 22-) & $4.71 \pm 1.70$ & \\
\hline Onset & & 0.15 \\
\hline Acute (<6 months) & $4.37 \pm 1.76$ & \\
\hline Chronic ( $\geq 6$ months) & $4.69 \pm 1.84$ & \\
\hline Type of injury & & 0.64 \\
\hline Complete & $4.69 \pm 1.91$ & \\
\hline Incomplete & $4.60 \pm 1.66$ & \\
\hline ASIA impairment scale & & \\
\hline A & & \\
\hline B & & \\
\hline C & & \\
\hline D & & \\
\hline NLI & & \\
\hline Thorvical & & \\
\hline & & \\
\hline
\end{tabular}


Table 5. Continued

\begin{tabular}{lcc}
\hline \multicolumn{1}{c}{ Variable } & $\begin{array}{c}\text { Pain intensity } \\
\text { (NRS) }\end{array}$ & p-value \\
\hline Type of injury \& NLI & & 0.47 \\
Complete, paraplegia & $4.50 \pm 1.58$ & \\
\hline Incomplete, paraplegia & $4.29 \pm 1.79$ & \\
\hline Complete, tetraplegia & $4.70 \pm 1.76$ & \\
\hline Incomplete, tetraplegia & $4.68 \pm 1.93$ & \\
Etiology of injury & & 0.27 \\
\hline Traumatic & $4.44 \pm 1.75$ & \\
\hline Non-traumatic & $4.71 \pm 1.92$ & \\
Locomotion & & 0.43 \\
\hline Wheelchair dependent & $4.57 \pm 1.76$ & \\
\hline Gait & $4.35 \pm 1.94$ & \\
KSCIM-III & & 0.17 \\
\hline Operation & & 0.81 \\
\hline Performed & $4.53 \pm 1.76$ & \\
\hline Not performed & $4.44 \pm 2.17$ & \\
\hline Spasticity & & 0.53 \\
\hline Spastic & $4.44 \pm 1.83$ & \\
\hline None & $4.58 \pm 1.78$ & \\
\hline Pain subtype & & $<0.001^{*}$ \\
\hline At level & $3.14 \pm 1.03$ & \\
\hline Below level & $4.51 \pm 1.77$ & \\
\hline
\end{tabular}

Values are presented as mean \pm standard deviation.

NRS, Numerical Rating Scale; BDI-II, Beck Depression Inventory 2nd edition; GDS, Geriatric Depression Scale; ASIA, American Spinal Injury Association; NLI, neurological level of injury; KSCIM-III, Korean version of the Spinal Cord Independence Measure 3rd edition.

${ }^{*} \mathrm{p}<0.05$ according to the independent $\mathrm{t}$-test.

clinical factors in patients with NP is shown in Table 5. The mean NRS score in women was $4.90 \pm 1.79$, which was significantly higher than that in men $(4.37 \pm 1.79 ; \mathrm{p}=0.03)$. In terms of pain subtype categories, we compared those with at-level SCI pain only with those with below-level SCI pain only. The mean NRS score for below-level SCI pain was $4.51 \pm 1.77$, which was significantly higher than that for at-level SCI pain (mean NRS, 3.14 $\pm 1.03 ; \mathrm{p}<0.001$ ). No statistically significant tendency in pain intensity was found in the groups classified using other variables.

Pain intensity used clinically as a therapeutic threshold for medication

The cut-off value of the NRS was determined on the

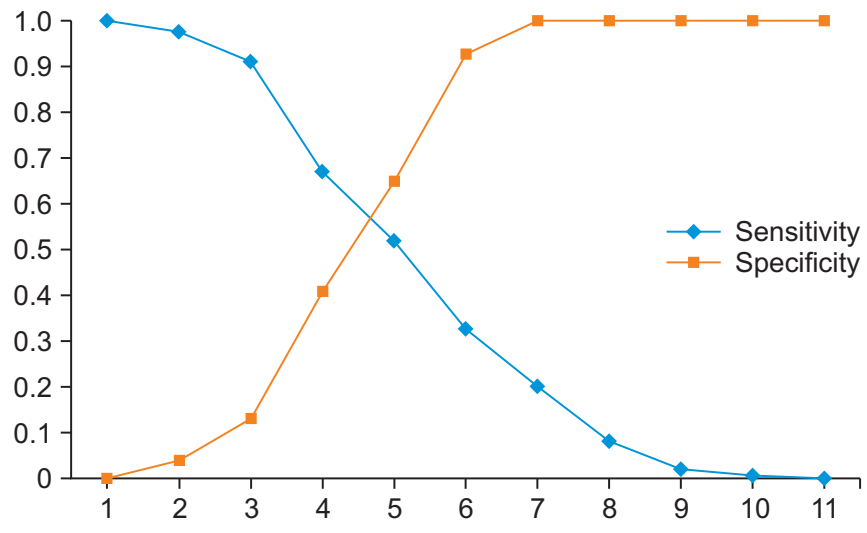

Fig. 1. Cut-off point for the Numerical Rating Scale discriminating between those who took pain medication and those who did not.

basis of sensitivity and specificity, corresponding to the different total scores. ROC curve analysis identified a score of 4.5 as the optimal cut-off value (values of the area under the curve ranged from 0.55 to $0.70 ; \mathrm{p}=0.006$ ). The graph plotting the cut-off point optimizing the sensitivity and specificity values showed a cut-off point of $\geq 4.5$ points as the most appropriate value for discriminating between those who took pain medication and those who did not (Fig. 1).

\section{DISCUSSION}

This study was the first to analyze the prevalence and other dynamics of NP in Korean patients with SCI. In previous studies, the prevalence of NP in patients with SCI has been estimated to range from $30 \%$ to $90 \%[1,17,18]$. In a systematic review and meta-analysis to consider the pooled point prevalence of NP post-SCI, prevalence rates for NP were reported to be $53 \%$ [4]. Although there is a consensus that NP is a common complication post-SCI, there are no agreed criteria to clearly define and classify SCI-related NPs. Many different classification schemes have been reported [19], and there have been widely varying estimates of the prevalence of various types of pain post-SCI. We found the prevalence of NP in patients with SCI was $69.1 \%$ according to the most recently upgraded and validated ISCIP classification, which was higher than that of other SCI cohorts. It is expected that future studies applying the ISCIP classification in a clinical setting will provide a more accurate understanding of SCI-related NP. 
Some studies report that NP is more prevalent in patients with paraplegia [20], incomplete lesions or traumatic SCIs [20,21], women [1], older patients [22], and patients with depression or anxiety [23]. However, other studies have reported contradictory findings $[10,24]$.

In this study, traumatic SCI clearly had a higher NP prevalence than non-traumatic SCI, although this was not found to be significantly different when adjusting for other variables. While many studies have compared traumatic and non-traumatic SCI, most studies have reported no statistical significance in relation to NP. However, the overall NP prevalence in patients with traumatic SCI has been found to be higher than that in patients with nontraumatic SCI [20]. A retrospective comparative cohort study involving 174 patients with SCI in Norway reported NP was more prevalent in those with traumatic SCI (57\% vs. $43 \%$ ); however, this finding was not statistically significant [25]. Similarly, in a meta-analysis recording the pooled prevalence of NP post-SCI, patients with traumatic SCI had a higher prevalence rate for NP $(43 \%$ vs. $38 \%$ ) [4]. However, it has also been shown that patients with traumatic SCIs tend to have complete lesions more frequently that are associated with a worse prognosis for neurologic improvement than those with non-traumatic SCIs $[10,25,26]$. In addition, people with non-traumatic SCI are significantly more likely to have paraplegia than tetraplegia [27]. We consider that the different mechanisms of traumatic SCI and non-traumatic SCI could explain the difference in the generation of NP and clinical characteristics; however, further research is needed to substantiate this.

In a study undertaken at a multidisciplinary pain center in Switzerland [6], depression was reported in 53\% of patients with SCI-related NP and was reported to be more common than in patients without pain [3]. Similar to previously reported findings [2], a significant correlation was found between higher levels of depression and higher NP prevalence in this study. Several studies have suggested that the presence of NP causes depression in the patient population with SCI. In addition to difficulties involved in pain treatment, pain is a source of considerable psychological distress for patients with SCI, and has been linked to depression and mental health $[3,28]$. In a recent study, a multidisciplinary cognitive behavioral program improved pain intensity and anxiety among patients with SCI-related NP, which suggests that mood may also affect
NP [29]. Furthermore, some studies have suggested that circulating pro-inflammatory cytokines that occur after SCI are associated with the development of both pain and depression [30]. Further cohort studies are required to identify the correlation between pain and depressive mood, to ensure that optimal pain management and assessment involving psychosocial characteristics of pain conditions post-SCI can be undertaken.

In terms of demographics, the only significant relationship identified in this study was between marital status and NP prevalence. Rita et al. reported that pain intensity among married patients was higher than that among single patients with traumatic SCI [31]. In one study, a univariate analysis of a cohort of patients with traumatic SCI found that married patients reported more pain interference 2 years post-injury than single patients [28]. Some studies have reported greater pain-related catastrophizing might be expected in the presence of someone who gives distress-relieving responses and responds solicitously to pain behavior (e.g., a spouse) [32]. According to these theories, comfort, care, and help provided by spouses could aggravate the pain and could explain why NP prevalence was found to be higher in the married patients in our study.

As with most relevant studies, we did not find a statistically significant difference in NP prevalence among the other clinical characteristics, including functional status. Several studies have highlighted that patients in pain have a lower degree of independence [33]. However, those studies most frequently used assessments that included various items related to quality of life (QOL) or social functioning, rather than motor ability alone [33]. Pain and pain interference appear to be separate issues in terms of the degree of physical restriction, and seem to have a secondary effect on the overall function of daily activities through causing depressed mood and a decrease in motivation.

In previous studies concerning SCI-related NP, average visual analog scale (VAS) scores ranged from 5.16 to $7.09[34,35]$ and from $27 \%$ to $58 \%$ in patients reporting severe pain (NRS or VAS >6) [3]. However, the prevalence of severe pain in our patient population was low (15.7\%); therefore, the average NRS score concerning NP was low (mean NRS score, 4.52 \pm 1.80 ).

Pain descriptions in our study differed from those of previous studies. In our study, the most commonly re- 
ported description of SCI-related NP was tingling (50.6\%), followed by a squeezing type of pain $(6.3 \%)$ and painful cold (6.3\%). However, other studies have reported that patients more commonly complained of hot burning pain, pricking, stabbing, numbness, or electric-type pain $[6,35]$. No multiple input boxes were available for patients to describe NP in our hospital admission notes; therefore, not all patients gave responses concerning all of their pain descriptions, even though they may have experienced several differing types of pain. As such, a limitation of our study was that we selected only the main pain description to ensure the accuracy of our findings. Furthermore, $36.0 \%$ of patients in our study had no information recorded concerning pain description, despite experiencing NP.

Drug use in treating SCI-related NP remains controversial. The pharmacological management guidelines for NP recommend first-line medications, such as gabapentin/ pregabalin (antiepileptics, TCAs, or topical lidocaine), and second-line medications, such as tramadol or high potent opioids. Our patient population was primarily being treated for SCI-related NP with anti-epileptic medication, TCAs, tramadol, and opioids as first- or second-line medication [36]. Analgesics have also been prescribed for patients with NP. This is likely to be because many clinicians frequently prescribe analgesics for ill-defined or refractory NP in accordance with conventional practice [6], as NP usually presents as ill-defined and refractory. However, we were not able to accurately determine whether our study patients had been administered this medication for other causes of pain.

Many studies have reported that NP intensity was not related to injury characteristics or demographic variables $[6,24]$. In contrast to previous studies $[6,10,35]$, our study found that pain subtype and sex were related to pain intensity. Although not statistically significant, patients with below-level SCI pain were more likely to report their pain as worse than those with at-level SCI pain in some studies involving patients with SCI [37]. At-level SCI pain is known to result from damage to roots and nerves at or near to the level of injury due to the localization characteristics of pain, and below-level SCI pain is known to be due to damage to the ascending sensory tract and sensory-related central nervous system $[3,5]$. We consider these distinct mechanisms may affect pain severity differently. However, due to the small number of patients with at-level SCI pain only ( $\mathrm{n}=14)$, our results should be interpreted with caution. Females are generally known to have lower pain thresholds, a greater ability to discriminate, higher pain ratings, and less tolerance of pain than males, despite being limited to nociceptive pain, which may explain our study findings in part [38]. Some studies that evaluated experimental SCI pain conducted on rats suggested that the magnitude of symptoms concerning SCI pain may differ between sexes [39]. However, further studies are needed to explain the possible mechanistic differences involved. Although several studies have identified an interactive association between SCI pain severity and the degree of mood disturbance [2,23], our study findings indicated that the degree of depressive mood was not related to pain intensity, and was only related to the prevalence of NP.

Our findings indicated that not only were patients more likely to take medication for NP as it increased in intensity, but that an NRS score of 4.5 was the optimal cut-off value used clinically as a therapeutic threshold for medication. A cut-off value for pain is needed to differentiate between patients who require pain management (those with moderate and severe pain) and those who do not (those with mild pain). In patients with SCI, pain severity can be categorized into mild, moderate, and severe pain, using ranges from 0 to 3,4 to 6 , and 7 to 10 . This classification system has been shown to be effective in distinguishing pain intensity in terms of activity interference and psychosocial well-being $[33,40]$. Whether the cut-off value used in our study is an appropriate value as a treatment threshold requires further verification because it has not been proven that an NRS $>4.5$ indicates that treatment is required due to significantly more severe activity interference and lower QOL. However, this cut-off value for determining pain treatment applied in clinical practice did not significantly differ from that found in previous studies.

The small sample size in this study was not sufficient to detect significant values for subgroup analyses. Given the study's retrospective cross-sectional design, possible information bias and less control over variables were limitations of the study. Moreover, we could not identify a causal relationship between each variable or change of variables. In this study, only the dominant NP type was reported. Therefore, it is reasonable to assume that our findings may have underestimated the actual number of 
pain-related data. However, to the extent that this may have occurred, this underestimation is unlikely to affect our main conclusions.

In conclusion, $69.1 \%$ of the patients with SCI complained of NP, which was higher than the results of previous studies and highlights that NP is a major complication for patients with SCI. Being married and having a depressive mood were predictors for the presence of NP. Below-level SCI pain was more severe than at-level SCI pain, and females complained of more severe pain more often than males. When NP severity has an NRS $>4$, treatment planning for NP needs to be considered empirically according to each patient's individual condition. Obtaining more precise information concerning the clinical characteristics of NP is important for improved patient management, and may help with determining a more targeted therapeutic intervention for patients with SCI.

\section{CONFLICT OF INTEREST}

No potential conflict of interest relevant to this article was reported.

\section{ACKNOWLEDGMENTS}

This study was supported by the Department of Healthcare and Public Health Research, Korea National Rehabilitation Center, Ministry of Health \& Welfare, Korea (No. 20-H-01).

\section{AUTHOR CONTRIBUTION}

Conceptualization: Lee HJ, Han ZA. Methodology: Lee HJ, Kim HY, Kim TL, Ham DH. Formal analysis: Lee HJ, Kim HY, Kim EY, Son MK, Lee JJ, Kim TY. Project administration: Lee HJ, Kim HY. Visualization: Lee HJ, Kim HY, Sung JH. Writing - original draft: Lee HJ, Kim HY. Writing - review and editing: Lee HJ, Kim HY, Shin JW. Approval of final manuscript: all authors.

\section{REFERENCES}

1. Budh NC, Lund I, Ertzgaard P, Holtz A, Hultling C, Levi R, et al. Pain in a Swedish spinal cord injury population. Clin Rehabil 2003;17:685-90.

2. van Gorp S, Kessels AG, Joosten EA, Kleef MV, Patijn J.
Pain prevalence and its determinants after spinal cord injury: a systematic review. Eur J Pain 2015;19:5-14.

3. Siddall PJ, McClelland JM, Rutkowski SB, Cousins MJ. A longitudinal study of the prevalence and characteristics of pain in the first 5 years following spinal cord injury. Pain 2003;103:249-57.

4. Burke D, Fullen BM, Stokes D, Lennon O. Neuropathic pain prevalence following spinal cord injury: a systematic review and meta-analysis. Eur J Pain 2017;21:29-44.

5. Bryce TN, Biering-Sorensen F, Finnerup NB, Cardenas DD, Defrin R, Lundeberg $\mathrm{T}$, et al. International spinal cord injury pain classification. Part I. Background and description. March 6-7, 2009. Spinal Cord 2012;50:413-7.

6. Mahnig S, Landmann G, Stockinger L, Opsommer E. Pain assessment according to the international spinal cord injury pain classification in patients with spinal cord injury referred to a multidisciplinary pain center. Spinal Cord 2016;54:809-15.

7. Jensen MP, Hoffman AJ, Cardenas DD. Chronic pain in individuals with spinal cord injury: a survey and longitudinal study. Spinal Cord 2005;43:704-12.

8. Friedman AH, Nashold BS Jr. DREZ lesions for relief of pain related to spinal cord injury. J Neurosurg 1986;65:465-9.

9. Margolis JM, Juneau P, Sadosky A, Cappelleri JC, Bryce TN, Nieshoff EC. Health care resource utilization and medical costs of spinal cord injury with neuropathic pain in a commercially insured population in the United States. Arch Phys Med Rehabil 2014;95:227987.

10. Werhagen L, Budh CN, Hultling C, Molander C. Neuropathic pain after traumatic spinal cord injury: relations to gender, spinal level, completeness, and age at the time of injury. Spinal Cord 2004;42:665-73.

11. Perry KN, Nicholas MK, Middleton J. Spinal cord injury-related pain in rehabilitation: a cross-sectional study of relationships with cognitions, mood and physical function. Eur J Pain 2009;13:511-7.

12. Kirshblum SC, Burns SP, Biering-Sorensen F, Donovan W, Graves DE, Jha A, et al. International standards for neurological classification of spinal cord injury (revised 2011). J Spinal Cord Med 2011;34:535-46.

13. Beck AT, Steer RA, Brown GK. Beck Depression Inventory. 2nd ed. San Antonio, TX: Psychological Corp.; 
1996.

14. Yesavage JA, Brink TL, Rose TL, Lum O, Huang V, Adey M, et al. Development and validation of a geriatric depression screening scale: a preliminary report. J Psychiatr Res 1982;17:37-49.

15. Akpinar P, Atici A, Ozkan FU, Aktas I, Kulcu DG, Sari A, et al. Reliability of the modified Ashworth scale and modified Tardieu scale in patients with spinal cord injuries. Spinal Cord 2017;55:944-9.

16. Cho DY, Shin HI, Kim HR, Lee BS, Kim GR, Leigh JH, et al. Reliability and validity of the Korean version of the spinal cord independence measure III. Am J Phys Med Rehabil 2020;99:305-9.

17. Adriaansen JJ, Post MW, de Groot S, van Asbeck FW, Stolwijk-Swuste JM, Tepper M, et al. Secondary health conditions in persons with spinal cord injury: a longitudinal study from one to five years post-discharge. J Rehabil Med 2013;45:1016-22.

18. Werhagen L, Aito S, Tucci L, Strayer J, Hultling C. 25 years or more after spinal cord injury: clinical conditions of individuals in the Florence and Stockholm areas. Spinal Cord 2012;50:243-6.

19. Putzke JD, Richards JS, Hicken BL, Ness TJ, Kezar L, DeVivo M. Pain classification following spinal cord injury: the utility of verbal descriptors. Spinal Cord 2002;40:118-27.

20. Vall J, Costa CM, Tde JS, Costa SB. Neuropathic pain characteristics in patients from Curitiba (Brazil) with spinal cord injury. Arq Neuropsiquiatr 2011;69:64-8.

21. Teixeira MJ, Paiva WS, Assis MS, Fonoff ET, Bor-SengShu E, Cecon AD. Neuropathic pain in patients with spinal cord injury: report of 213 patients. Arq Neuropsiquiatr 2013;71:600-3.

22. Stormer S, Gerner HJ, Gruninger W, Metzmacher K, Follinger S, Wienke C, et al. Chronic pain/dysaesthesiae in spinal cord injury patients: results of a multicentre study. Spinal Cord 1997;35:446-55.

23. Perry KN, Nicholas MK, Middleton J, Siddall P. Psychological characteristics of people with spinal cord injury-related persisting pain referred to a tertiary pain management center. J Rehabil Res Dev 2009;46:57-67.

24. Nakipoglu-Yuzer GF, Atci N, Ozgirgin N. Neuropathic pain in spinal cord injury. Pain Physician 2013;16:25964.

25. Gedde MH, Lilleberg HS, Abmus J, Gilhus NE, Rekand
T. Traumatic vs non-traumatic spinal cord injury: a comparison of primary rehabilitation outcomes and complications during hospitalization. J Spinal Cord Med 2019;42:695-701.

26. Werhagen L, Hultling C, Molander C. The prevalence of neuropathic pain after non-traumatic spinal cord lesion. Spinal Cord 2007;45:609-15.

27. McKinley WO. Nontraumatic spinal cord injury: etiology, incidence and outcome. In: Kirshblum S, Campagnolo DI, DeLisa JA, editors. Spinal cord medicine. Philadelphia, PA: Lippincott Williams \& Wilkins 2002. p. 471-79.

28. Putzke JD, Richards JS, Hicken BL, DeVivo MJ. Interference due to pain following spinal cord injury: important predictors and impact on quality of life. Pain 2002;100:231-42.

29. Heutink M, Post MW, Luthart P, Schuitemaker M, Slangen S, Sweers J, et al. Long-term outcomes of a multidisciplinary cognitive behavioural programme for coping with chronic neuropathic spinal cord injury pain. J Rehabil Med 2014;46:540-5.

30. Lees JG, Fivelman B, Duffy SS, Makker PG, Perera CJ, Moalem-Taylor G. Cytokines in neuropathic pain and associated depression. In: Finn DP, Leonard BE, editors. Pain in psychiatric disorders. Basel, Switzerland: Karger; 2015. p. 51-66.

31. Aquarone RL, Nogueira PC. Central neuropathic pain: implications on quality of life of spinal cord injury patients. Revista Dor 2015;16:280-4.

32. Giardino ND, Jensen MP, Turner JA, Ehde DM, Cardenas DD. Social environment moderates the association between catastrophizing and pain among persons with a spinal cord injury. Pain 2003;106:19-25.

33. Forchheimer MB, Richards JS, Chiodo AE, Bryce TN, Dyson-Hudson TA. Cut point determination in the measurement of pain and its relationship to psychosocial and functional measures after traumatic spinal cord injury: a retrospective model spinal cord injury system analysis. Arch Phys Med Rehabil 2011;92:41924.

34. Celik EC, Erhan B, Lakse E. The clinical characteristics of neuropathic pain in patients with spinal cord injury. Spinal Cord 2012;50:585-9.

35. Jang JY, Lee SH, Kim M, Ryu JS. Characteristics of neuropathic pain in patients with spinal cord injury. Ann Rehabil Med 2014;38:327-34. 
36. Attal N, Cruccu G, Baron R, Haanpaa M, Hansson P, Jensen TS, Nurmikko T, et al. EFNS guidelines on the pharmacological treatment of neuropathic pain: 2010 revision. Eur J Neurol 2010;17:1113-e88.

37. Nagoshi N, Kaneko S, Fujiyoshi K, Takemitsu M, Yagi $\mathrm{M}$, Iizuka S, et al. Characteristics of neuropathic pain and its relationship with quality of life in 72 patients with spinal cord injury. Spinal Cord 2016;54:656-61.

38. Berkley KJ. Sex differences in pain. Behav Brain Sci
1997;20:371-80.

39. Gaudet AD, Ayala MT, Schleicher WE, Smith EJ, Bateman EM, Maier SF, et al. Exploring acute-to-chronic neuropathic pain in rats after contusion spinal cord injury. Exp Neurol 2017;295:46-54.

40. Hanley MA, Masedo A, Jensen MP, Cardenas D, Turner JA. Pain interference in persons with spinal cord injury: classification of mild, moderate, and severe pain. J Pain 2006;7:129-33. 